\title{
Analisando uma técnica de elicitação baseada na criatividade combinacional - um estudo comparativo
}

\author{
Lyrene Fernandes Silva ${ }^{1}$ \\ Rafael Pinto ${ }^{1}$ \\ Márcia Lucena ${ }^{1}$
}

\begin{abstract}
Resumo: Diante da crescente competitividade do mercado, a Engenharia de Requisitos tem buscado, através de técnicas de criatividade, fornecer meios para elicitação de requisitos úteis e inovadores. Dentre estas técnicas há a criatividade combinacional, que possibilita a produção de novas ideias através da combinação de ideias antigas não familiares. Trabalhos nesta linha têm demonstrado bons resultados, mas poucos comparam esta técnica com outras. Assim, o objetivo deste trabalho é comparar os resultados alcançados na elicitação usando e não usando uma abordagem combinacional. A elicitação teve a participação de 17 usuários assíduos de um sistema acadêmico, dos quais 9 utilizaram a abordagem combinacional e 8 uma abordagem baseada em entrevista. A elicitação foi realizada numa reunião, na qual os participantes criaram, individualmente, $42 \mathrm{re-}$ quisitos válidos, 21 por cada técnica. Destes, apenas 9 foram avaliados como úteis e originais. Em termos quantitativos, não houve grande diferença na quantidade de requisitos ao mesmo tempo úteis e originais que foram gerados pelas duas técnicas. Entretanto, mais requisitos úteis foram gerados com a técnica de entrevista. Em termos qualitativos, os participantes sugeriram que uma abordagem mista facilitaria a elaboração de ideias inovadoras.
\end{abstract}

Palavras-chave: Criatividade Combinacional, Elicitação de Requisitos, Entrevista, Estudo Empírico.

\begin{abstract}
Faced with the market's growing competitiveness, Requirements Engineering has sought, through creativity techniques, to provide means to elicit useful and innovative requirements. Among these techniques, there is the combinational creativity, which allows the development of new ideas through the combination of non-familiar old ideas. Works that follow this technique have shown good results, but only a few of them compare this technique to others. Thus, the goal of this work is to compare the results achieved in elicitation using and not using a combinational approach. The elicitation process had, as participants, 17 regular users of an academic system, 9 of which used the combinational approach while the remaining 8 used an interview-based approach. The elicitation was carried out in a meeting, in which the participants individually created 42 valid requirements, 21 for each technique. Out of the requirements that were created, only 9 were considered useful and original. In quantitative terms, there was not much difference in the number of requirements that were both original and useful generated by each of the two techniques. However, a greater number of useful requirements were generated using the interview technique. In qualitative terms, participants suggested that to use a mixed approach would favor the creativity.
\end{abstract}

Keywords: Combinational Creativity, Empirical Study, Interview, Requirements Elicitation.

\section{Introdução}

A Engenharia de Requisitos (ER) é o processo de descobrir o propósito de um sistema, através da identificação das partes interessadas (stakeholders) e suas necessidades, bem como documentação destas informações

\footnotetext{
${ }^{1}$ Programa de Pós-Graduação em Sistemas e Computação (PPGSC), UFRN, Campus Central - BR 101 - Natal (RN) - Brasil \{lyrene, rrafaelpinto, marcia.lucena@gmail.com\}
}

http://dx.doi.org/10.5335/rbca.v9i4.6786

Revista Brasileira de Computação Aplicada (ISSN 2176-6649), Passo Fundo, v. 9, n. 4, p. 105-119, dez. 2017105 
de uma maneira passível de análise, comunicação e posterior implementação [1]. Além disso, a ER é reconhecida como sendo, pelo menos em parte, um processo criativo no qual os stakeholders e os engenheiros trabalham juntos para criar ideias, eventualmente expressas como novos requisitos para novos produtos, serviços e sistemas, a fim de obter uma vantagem competitiva [2]. No entanto, stakeholders, em algumas situações, não identificam como melhorar seus produtos ou como torná-los inovadores ou diferentes. Esta identificação é ainda mais difícil quando se trata de um novo produto ou de um mercado desconhecido [3]. Mesmo sistemas de software similares necessitam se distinguir uns dos outros, oferecendo recursos úteis e únicos para que sejam competitivos [4].

A criatividade é definida como a habilidade em produzir algo inovador (original e inesperado) e apropriado (útil e adaptável para as atividades requeridas) [5]. Inspirados nesse conceito, Maiden e outros [6] definem que requisitos criativos são aqueles considerados inovadores e apropriados, sendo esta a definição que utilizamos neste trabalho. Técnicas de elicitação baseadas na criatividade visam promover o entendimento das expectativas implícitas do cliente conduzindo a criação de requisitos originais, para que assim, as empresas possam se diferenciar dos concorrentes e atrair novos clientes [7][8].

Neste contexto, algumas técnicas de criatividade como Cenários [9], Workshops [10], Design Thinking [11] e Criatividade Combinacional $[4,12]$ têm sido usadas para incitar os stakeholders a produzirem requisitos criativos. Em relação a criatividade combinacional, podemos citar o framework definido em [4], que propõe a criação de requisitos através da combinação de palavras extraídas de uma rede social por meio de algoritmos de Processamento de Linguagem Natural (PLN), Análise de Rede Social e Análise de Similaridade. Assim, conjuntos de pares de palavras (substantivos e verbos) não familiares são disponibilizados aos stakeholders para que os mesmos criem requisitos utilizando-as. Um experimento realizado por estes pesquisadores mostrou que o framework proposto é capaz de criar requisitos criativos.

Inspirados neste framework, nós delineamos e experimentamos uma abordagem de elicitação baseada na criatividade combinacional [13]. Em [12], avaliamos se algumas simplificações da abordagem de Bhowmik [4] também produziriam requisitos criativos. Estas simplificações visaram facilitar o trabalho dos Engenheiros de Requisitos e possibilitar o uso dos recursos disponíveis no contexto organizacional da equipe de desenvolvimento. Dentre as mudanças podemos citar: não utilizamos análise de rede social e análise de similaridade, a fonte de textos que originou as palavras foi a documentação do software (documento de visão e especificação de casos de uso), as palavras escolhidas foram aquelas mais e menos frequentes, classificadas segundo sua categoria gramatical (substantivos, verbos, adjetivos, etc), a localização do stakeholder durante a elicitação podia ser remota; a quantidade de participantes e a forma de avaliar os requisitos criados também foram distintos daqueles de [4].

Em [13], foram catalogadas variabilidades que podem ser consideradas neste tipo de processo de elicitação. [12] e [13] apresentaram experimentos cujos resultados demonstraram que mesmo diante de algumas variações também foi possível criar requisitos inovadores para o software em questão. Entretanto, estes dois trabalhos e o trabalho original proposto por Bhowmik [4] não consideraram em seus experimentos uma outra técnica de elicitação para servir como base de comparação dos resultados obtidos. Assim, o presente trabalho apresenta nossa experiência em instanciar a abordagem definida em [13] e comparar seus resultados com os resultados obtidos numa elicitação baseada em entrevista.

O restante deste trabalho está organizado da seguinte forma: na seção 2, apresentamos trabalhos que relatam o uso de técnicas de elicitação baseadas em criatividade; na seção 3, detalhamos a abordagem e o apoio ferramental utilizado; na seção 4, discutimos como aconteceu o experimento, quais os resultados obtidos, as ameaças e as lições aprendidas; por fim, na seção 5, discorremos sobre as conclusões e trabalhos futuros.

\section{Fundamentação teórica e trabalhos relacionados}

A criatividade pode ser definida como um processo mental que envolve a geração de ideias inéditas e inovadoras [14] e pode ser classificada como exploratória, combinacional ou transformacional [15]. No contexto da engenharia de requisitos, Maiden [16] afirma que essa classificação varia de acordo com as técnicas e heurísticas utilizadas. Na criatividade exploratória, os requisitos criativos são obtidos por explorar as possibilidades em um espaço de busca delimitado por regras e restrições de tarefas específicas para o sistema de software pretendido. A criatividade combinacional é alcançada fazendo conexões desconhecidas entre requisitos conhecidos em um ambiente familiar. Ou seja, é caracterizada pela solução encontrada em uma combinação improvável. Enquanto,

Revista Brasileira de Computação Aplicada (ISSN 2176-6649), Passo Fundo, v. 9, n. 4, p. 105-119, dez. 2017106 
a criatividade transformacional é realizada ao desafiar as restrições sobre o espaço de busca, extrapolando esse espaço de restrições.

A Figura 2 ilustra conceitualmente os três tipos de criatividade. Tomemos como exemplo o desenvolvimento hipotético de um sistema de Home Care. Assumindo um requisito denominado Registrar a Temperatura do Paciente. O espaço de busca pode ser limitado pelo tipo de hardware disponível e o custo de implementação, ilustrado na figura pelo círculo azul. Assim, Termômetro de Contato e Termômetro Infravermelho são soluções que poderiam ser encontradas dentro do espaço de busca usando criatividade exploratória. A combinação dessas duas soluções poderia produzir uma outra solução, neste caso utilizando criatividade combinacional. Enquanto, extrapolar as regras definidas ou desconsiderá-las, em busca de uma solução, como por exemplo, desenvolver uma Pulseira que aufira a temperatura e registre-a de tempos em tempos no sistema, seria obtida pela criatividade transformacional.

Figura 1: Exemplo de como a criatividade pode ser classificada.

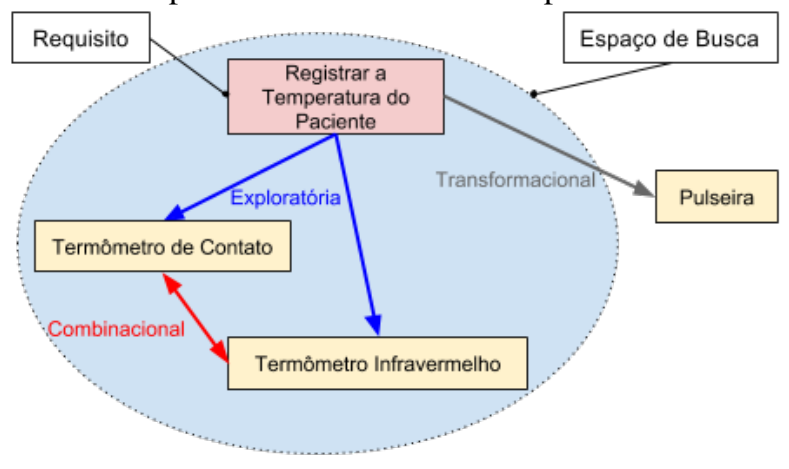

Dentre os trabalhos de elicitação de requisitos que consideram a criatividade como objetivo preponderante e que apresentam resultados experimentais, podemos citar a realização de workshops de requisitos [10], o EPMCreate [17, 18], um framework de criatividade combinacional [4] e uma abordagem que modifica este framework [12][13].

Em [10] relata-se a realização de workshops com o uso de técnicas de analogia para incentivar o pensamento criativo durante a elicitação. O estudo englobou a realização de 4 workshops, com duração de um dia cada, para gerar requisitos e ideias para um sistema de gestão de tráfego aéreo (CORA-2). Cada workshop envolveu entre 16 e 20 participantes. Os três primeiros workshops geraram 201 novas ideias para o CORE-2. Além disso, o grupo utilizou estes 201 novos requisitos e ideias como base para escrever casos de uso e cenários mais precisos que, por sua vez, permitiu a elaboração e especificação de requisitos utilizando ART-SCENE [19]. ART-SCENE é um ambiente de software que gera automaticamente cenários a partir das especificações dos casos de uso, em seguida, orienta os stakeholders a percorrer estes cenários para descobrir novos requisitos. O quarto workshop foi realizado para os participantes selecionarem as ideias e priorizarem-nas de acordo com sua relevância para o sistema CORA-2 (ou seu sucessor CORA-3).

Em [18] é proposta uma técnica denominada EPMcreate (Acrônimo em inglês de EPM Creative Requirements Engineering Technique), adaptada a partir da Técnica EPM (Acrônimo em inglês de Elementary Pragmatic Model). Ela consiste em 16 passos, onde, em cada um deles o problema é analisado de acordo com um dos comportamentos identificados pelo EPM. Cada um desses passos determina como o Engenheiro de Requisitos deve olhar para o problema, a partir dos pontos de vistas dos stakeholders. A viabilidade e eficácia desta técnica na elicitação de requisitos foi demonstrada por experimentos em dois projetos com características muito diferentes. Cada experimento comparou o desempenho de duas equipes de análise, um deles utilizando EPMCreate e o outro utilizando Brainstorm. Cada experimento contou com a participação de 8 stakeholders. Os resultados dos experimentos foram analisados quantitativamente, contando o número de ideias e requisitos gerados, e qualitativamente, comparando a viabilidade e a inovação das ideias e requisitos. Em termos quantitativos, a equipe utilizando EPMcreate conseguiu gerar 169 ideias e requisitos, ao passo que a outra equipe gerou 65. As ideias e requisitos criadas foram validadas segundo os critérios: requisitos novos e realizáveis; novos, mas não realizáveis; já conhecidos, mas não realizáveis; ou já conhecidos e realizáveis. Com isso, 66 das ideias e requisitos criados utilizando EPM-

Revista Brasileira de Computação Aplicada (ISSN 2176-6649), Passo Fundo, v. 9, n. 4, p. 105-119, dez. 2017107 
create foram considerados novos e realizáveis, enquanto que a técnica de Brainstorm obteve apenas 18 requisitos com esse score.

Em [4] é proposto um framework que, com o uso de algoritmos de Processamento de Linguagem Natural (PLN), extrai pares de palavras que não tenham conexão a partir de requisitos e comentários dos stakeholders registrados em uma rede social ou sistema de acompanhamento de tarefas (Bugzilla ${ }^{1}$, por exemplo). PLN é usado para descobrir a estrutura temática (tópicos) por trás de grandes textos e assim identificar a associação de tipos diferentes de ideias. Após a descoberta destes tópicos, pares de palavras (substantivos e verbos) são escolhidos e disponibilizados aos especialistas no domínio da aplicação, a fim de que possam propor requisitos inovadores. Este framework foi validado por um estudo de caso no qual participou 1 analista que gerou 13 ideias para dois sistemas. Estes requisitos foram validados por 28 especialistas do domínio que apontaram 10 daquelas ideias como sendo originais e relevantes.

Em [12], foi apresentada uma variação da abordagem proposta em [4]. Esta variação simplifica alguns passos e modifica algumas características das palavras extraídas da documentação do software, uma vez que o contexto organizacional que se desejava atender era diferente do proposto originalmente em [4]. O objetivo era usar a documentação do software como ponto de partida para a extração de palavras relevantes e os algoritmos de PLN foram ajustados para extrair uma lista de verbos e substantivos, considerados os mais e menos frequentes do texto. A abordagem foi validada por um estudo de caso, no qual participaram 11 usuários que geraram 20 requisitos válidos, estes requisitos foram avaliados por 1 analista que apontou 11 requisitos como sendo novos.

A Tabela 1 resume algumas características desses 4 trabalhos e acrescenta, nas duas últimas colunas, as técnicas de Entrevista e Combinacional cujas propriedades explicamos e comparamos nas próximas seções.

Tabela 1: Comparação dos resultados obtidos com o uso de técnicas de elicitação focadas na criatividade

\begin{tabular}{|c|c|c|c|c|c|c|c|}
\hline \multirow{7}{*}{ 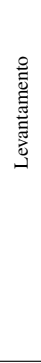 } & Característica & Bhowmik, T. (2014) [4] & Pinto, R. (2015) [12] & Mich, L. (2005) [18] & Maiden, N. (2004) [10] & Entrevista & Combinacional \\
\hline & $\begin{array}{l}\text { Localização dos } \\
\text { Stakeholders }\end{array}$ & Presencial & Remota & Presencial & Presencial & Presencial & Presencial \\
\hline & Tipo de Atividade & Individual & Individual & Em grupos de pares & Em grupos & Individual & Individual \\
\hline & $\begin{array}{l}\text { Perfil dos } \\
\text { Stakeholders }\end{array}$ & $\begin{array}{l}\text { Especialista do } \\
\text { domínio da aplicação }\end{array}$ & Usuário da aplicação & $\begin{array}{l}\text { Estudantes e } \\
\text { Analistas }\end{array}$ & $\begin{array}{l}\text { Gerente de projeto, } \\
\text { engenheiros de } \\
\text { requisitos, } \\
\text { especialistas no } \\
\text { domínio da aplicação }\end{array}$ & Usuários da aplicação & Usuários da aplicação \\
\hline & $\begin{array}{l}\text { Quantidade de } \\
\text { Stakeholders }\end{array}$ & 1 & 11 & 8 & $\begin{array}{l}\text { Entre } 16 \text { e } 20 \\
\text { membros em cada um } \\
\text { dos } 4 \text { workshops }\end{array}$ & 8 & 9 \\
\hline & $\begin{array}{l}\text { Tempo para Geração } \\
\text { das Ideias }\end{array}$ & 2 horas & Até 15 minutos & 2 horas & 3 dias & 14 minutos & 23 minutos \\
\hline & $\begin{array}{l}\text { Quantidade de Ideias } \\
\text { Geradas }\end{array}$ & 13 & 25 & 169 & 201 & 21 & 21 \\
\hline \multirow{4}{*}{ 急 } & Critério de Avaliação & $\begin{array}{l}\text { Requisitos } \\
\text { considerados } \\
\text { inovadores e } \\
\text { apropriados }\end{array}$ & $\begin{array}{l}\text { Requisitos } \\
\text { considerados novos } \\
\text { para o software } \\
\text { pretendido }\end{array}$ & $\begin{array}{l}\text { Critérios próprios: } \\
\text { novos e realizáveis; } \\
\text { novos, mas não } \\
\text { realizáveis; já } \\
\text { conhecidos, mas não } \\
\text { realizáveis; já } \\
\text { conhecidos e } \\
\text { realizáveis }\end{array}$ & $\begin{array}{l}\text { Requisitos } \\
\text { considerados } \\
\text { relevantes para o } \\
\text { software pretendido }\end{array}$ & $\begin{array}{l}\text { Requisitos } \\
\text { considerados úteis e } \\
\text { originais }\end{array}$ & $\begin{array}{l}\text { Requisitos } \\
\text { considerados úteis e } \\
\text { originais }\end{array}$ \\
\hline & Perfil dos Avaliadores & $\begin{array}{l}\text { Desenvolvedores com } \\
\text { experiência nos } \\
\text { softwares explorados }\end{array}$ & $\begin{array}{l}\text { Analista de Sistemas } \\
\text { com experiência no } \\
\text { desenvolvimento } \\
\text { original do software }\end{array}$ & $\begin{array}{l}\text { Gerente e } \\
\text { desenvolvedores do } \\
\text { projeto original }\end{array}$ & $\begin{array}{l}\text { Não deixa claro se } \\
\text { foram os mesmos } \\
\text { participantes ou } \\
\text { novos }\end{array}$ & $\begin{array}{l}\text { Usuários da aplicação } \\
\text { que participaram da } \\
\text { elicitação usando a } \\
\text { outra técnica }\end{array}$ & $\begin{array}{l}\text { Usuários da aplicação } \\
\text { que participaram da } \\
\text { elicitação usando a } \\
\text { outra técnica }\end{array}$ \\
\hline & Escala de Pontuação & Escala Likert & $\begin{array}{l}\text { Classificando } \\
\text { requisitos como } \\
\text { válidos, inválidos, } \\
\text { novos ou comuns }\end{array}$ & Não informado & Não informado & Escala Likert & Escala Likert \\
\hline & $\begin{array}{l}\text { Quantidade de } \\
\text { Avaliadores }\end{array}$ & 29 & 1 & Não informado & Os próprios autores & 10 & 10 \\
\hline
\end{tabular}

Além desses trabalhos relacionados podemos citar aqueles que usam técnicas de processamento de linguagem natural para identificar requisitos automaticamente a partir de reclamações em lojas de aplicativos [20] ou em repositórios de código fonte [21]. Entretanto, esse tipo de elicitação não foca a participação direta do fator humano como sendo vital para elaboração dos novos requisitos.

\footnotetext{
${ }_{1}<$ https://www.bugzilla.org/>
} 


\section{Técnica de elicitação de requisitos baseada na criatividade combinacional usada neste trabalho}

A abordagem aqui experimentada é uma variação da descrita em [12], que por sua vez foi inspirada na abordagem definida em [4]. A Figura 2 apresenta as atividades realizadas neste processo de elicitação e quem as realiza. O engenheiro de requisitos é responsável por preparar todos os insumos a serem utilizados pelos stakeholders (especialistas do domínio, por exemplo) realizando as seguintes atividades: i) Selecionar Fontes de Textos, estas fontes são os textos a partir dos quais as palavras serão extraídas; ii) Selecionar Palavras, na qual algoritmos de processamento de linguagem natural são usados para classificar e selecionar as palavras mais relevantes dos documentos; e iii) Definir Regras de Criação dos Requisitos, na qual são estabelecidas diretrizes para a combinação das palavras selecionadas. Enquanto os stakeholders são responsáveis por Criar Novos Requisitos usando como base as palavras geradas pelo engenheiro de requisitos e Validar Requisitos usando os critérios de utilidade e originalidade.

Figura 2: Processo de elicitação de requisitos utilizando criatividade combinacional

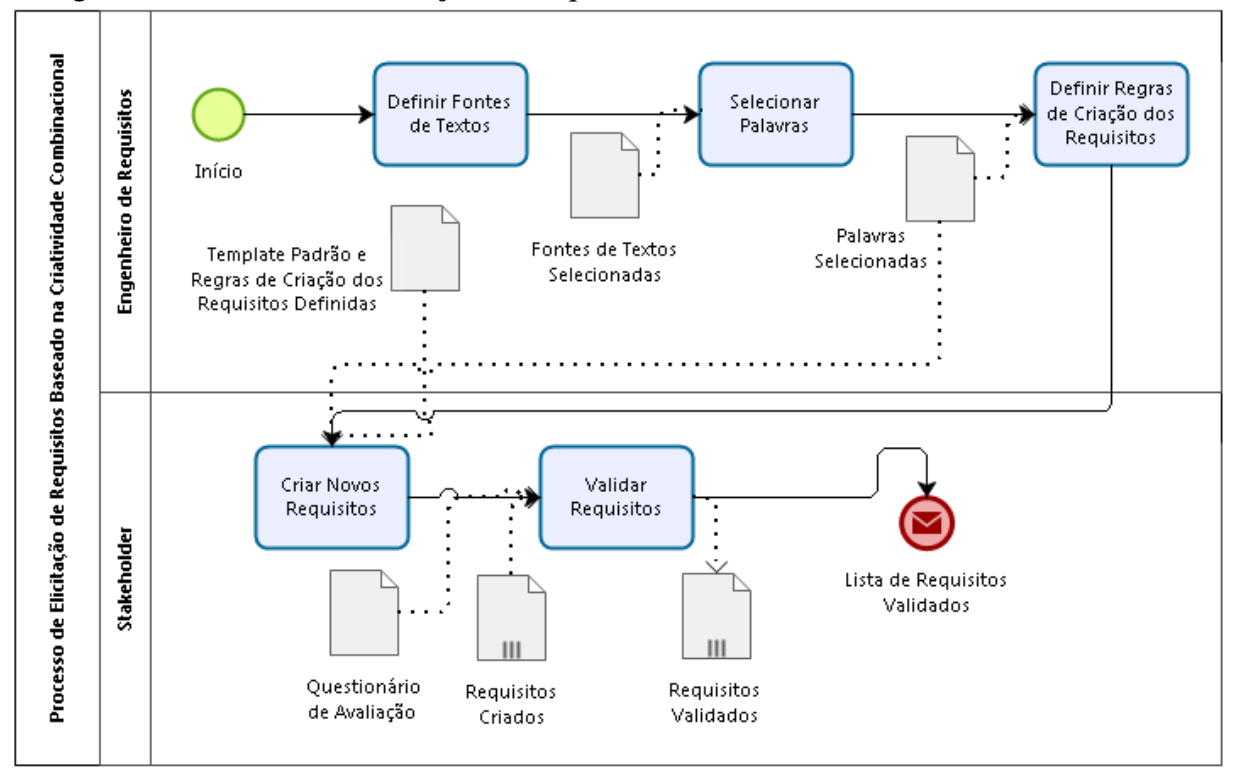

As principais características desta abordagem que a distingue das apresentadas em [4] e [12] são:

- A fonte de dados que origina as palavras relevantes são definidas pelo engenheiro de requisitos, podendo ser tanto internas quanto externas. As fontes de dados internas são textos considerados relevantes para o software em que se deseja levantar novos requisitos e devem ter relação direta com o domínio dele. Um exemplo dessa fonte de dados é a documentação do sistema. As fontes de dados externas devem ser compostas por textos relacionados à área de atuação do software, mas que não tenham sido elaborados pela equipe do projeto. Um exemplo deste tipo de fonte de dados é o log de reclamações sobre um outro sistema de software de um domínio correlato.

- As atividades são apoiadas por um protótipo de ferramenta chamada Ideasy que utiliza algoritmos de topic model usando LDA (Latent Dirichlet Allocation), uma das técnicas de processamento de linguagem natural mais utilizadas para este fim [22]. LDA é um modelo probabilístico usado para determinar os temas abordados em um texto, analisando a frequência com que as palavras aparecem. Para gerar o modelo LDA utilizamos um pacote em Python chamado Gensim, responsável por analisar o conteúdo textual e retornar uma lista de palavras/probabilidade para as palavras mais prováveis.

- O engenheiro de requisitos tem liberdade para configurar a ferramenta Ideasy a fim de gerar diferentes conjunto de palavras. Por exemplo, após definidas as fontes de dados, o engenheiro de requisitos pode definir quantas palavras deseja extrair de cada fonte. Caso não esteja satisfeito com o resultado do processamento, 
poderá gerar novamente as palavras alterando a quantidade de cada fonte de dados e o conjunto de stop words (palavras que não devem ser consideradas). Além disso, também é possível ao engenheiro de requisitos informar se deseja que as palavras disponibilizadas aos stakeholders sejam visualizadas em formato de lista ou de nuvem; ou até mesmo inserir, alterar ou excluir palavras, antes de disponibilizá-las aos participantes da elicitação.

- Os stakeholders devem criar novos requisitos utilizando uma palavra de cada conjunto (verbos e substantivos), mas eles não são obrigados a fazer o verbo incidir sobre o substantivo escolhido. Além disso, ao contrário do experimento em [4], os pares verbo-objeto não foram pré-definidos.

- Após a submissão de novos requisitos, os stakeholders devem avaliar os requisitos levantados pelos demais participantes. Esta etapa também é apoiada pela ferramenta. Esta avaliação é realizada com base nos critérios de utilidade e originalidade utilizando a escala de Likert [23], com valores de um a cinco: 1 - Não concordo totalmente; 2 - Não concordo; 3 - Neutro ou indiferente; 4 - Concordo; e 5 - Concordo totalmente.

\section{Estudo prático da elicitação baseada em criatividade combinacional}

O objetivo da análise aqui relatada foi avaliar uma variação da abordagem definida em [12] e comparar os resultados obtidos com uma outra técnica de elicitação. A avaliação visa confirmar ou refutar se esta nova variação também possibilita a produção de requisitos criativos. Enquanto a comparação visa observar se utilizar a técnica resultaria em mais requisitos criativos do que não utilizá-la. Assim, nossa questão de pesquisa é: Esta técnica de elicitação produz mais requisitos criativos (úteis e inovadores) do que se simplesmente solicitássemos requisitos criativos aos usuários?

Planejamos e executamos um estudo que utiliza o módulo educacional de um sistema de gerência acadêmica, chamado Sigaa. O Sigaa é um sistema desenvolvido e mantido pela Universidade Federal do Rio Grande do Norte (UFRN) e foi escolhido porque atende às restrições da técnica: conter uma boa documentação escrita, a partir da qual pode-se extrair as palavras a serem utilizadas; e ser bastante utilizado por usuários assíduos aos quais temos acesso para solicitar requisitos e validá-los.

Os papéis definidos na abordagem foram distribuídos da seguinte forma. Dois dos autores deste artigo realizaram o papel de engenheiro de requisitos (como descrito na Figura 2), ficando encarregados de preparar e conduzir a elicitação: criando o projeto na ferramenta, definindo as fontes de informação, escolhendo o conjunto de palavras, compartilhando o formulário de criação e validação de requisitos. Enquanto 20 usuários do Sigaa realizaram o papel de stakeholders, os quais foram responsáveis por, quando solicitados, criar (17 usuários) e avaliar (20 usuários) os requisitos gerados.

A ferramenta Ideasy exerceu papel central no estudo, mas além dela foram utilizados os seguintes recursos: sala onde ocorreu a reunião de elicitação e validação; esta sala estava equipada com computadores para os participantes responderem aos formulários eletrônicos; as fontes de informação interna e externa, que neste caso foram fontes textuais (detalhadas na próxima seção); formulários de identificação pessoal aplicado no início do estudo, e formulário de avaliação final sobre a experiência em usar as técnicas de elicitação. A seguir, detalhamos como as atividades de preparação da elicitação e a execução foram realizadas.

\subsection{Preparação da elicitação}

O Sigaa está documentado utilizando uma versão open source da Wiki, denominado DokuWiki. Para obter o conteúdo textual da documentação, após termos o acesso liberado à mesma, utilizamos uma pequena aplicação em Python, responsável por ler o conteúdo disponível na DokuWiki e salvar diretamente em um projeto chamado Sigaa, na ferramenta Ideasy. Assim, cadastramos todo o conteúdo disponível referente ao módulo de graduação, removendo imagens, tabelas, menus e informações de perfis de acesso. Este conteúdo foi categorizado como fonte de dados interna.

Como fonte de dados externa o engenheiro de requisitos decidiu usar o log de opiniões de usuários em lojas de aplicativos móveis. Assim, o engenheiro de requisitos escolheu duas aplicações hospedadas no Google 
Play ${ }^{2}$, que pertencessem à categoria Educação. Para essa escolha, ele levou em consideração a quantidade de vezes que as aplicações foram baixadas pelos usuários e a quantidade de comentários realizados pelos usuários. As aplicações escolhidas foram o $\mathrm{Sisu}^{3}$ e o Gabaritar ${ }^{4}$.

A aplicação Sisu, desenvolvida pelo Ministério da Educação do Governo Federal, visa prover uma plataforma móvel (via smartphone) para consulta de informações do programa de mesmo nome. Em linhas gerais, este sistema permite que as instituições públicas de ensino superior ofereçam vagas para candidatos participantes do Exame Nacional do Ensino Médio (Enem). A aplicação já foi baixada por mais de 100 mil usuários (entre 100.000 e 500.000 downloads) e possuía, na época, 5.129 comentários, tendo uma avaliação de 4.4 pontos (em uma escala de 1 a 5 pontos).

A aplicação Gabaritar foi desenvolvida por uma empresa privada com sede em São Paulo. Ela permite que o usuário organize melhor os estudos para concursos públicos disponibilizando funcionalidades para registro de horários de estudo, resoluções de simulados, acompanhamento de desempenho, dentre outras. A aplicação também possui um alto número de downloads (entre 100.000 e 500.000), 1.956 comentários e uma avaliação de 4 pontos.

Após a escolha das duas aplicações, o engenheiro de requisitos realizou a extração dos comentários (reviews) dos usuários utilizando uma pequena aplicação em Java que criou especificamente para este fim. Ao final, a extração resultou em dois arquivos textos, cada um contendo os comentários referentes a cada sistema. Por fim, o engenheiro de requisitos vinculou estes arquivos como fontes de dados externas para o projeto criado.

Em seguida o engenheiro de requisitos solicitou à ferramenta que 20 substantivos e 20 verbos fossem extraídos das fontes de dados. Sendo destes 10 substantivos e 10 verbos com base na fonte de dados interna e 10 substantivos e 10 verbos com base na fonte de dados externa. O resultado dado pela ferramenta pode ser visualizado na tabela 2. Neste momento, as palavras que o engenheiro de requisitos julgou ser irrelevante foram substituídas por palavras que ele havia previamente planejado incluir na elicitação para tentar estimular os usuários a pensarem em características associadas a elas. As palavras excluídas foram: iniciativa, terra, rodar, ficar e residir. Enquanto as palavras incluídas, respectivamente, foram: whatsapp, facebook, fotografar, fraudar e personalizar.

Tabela 2: Palavras mais relevantes, resultado do processamento das fontes de dados e substituição feita pelo engenheiro de requisitos.

\begin{tabular}{l|l|ll|l|l} 
Classificação & Palavra & Origem & Classificação & Palavra & Origem \\
\hline Substantivo & disciplina & Externa & Verbo & controlar & Externa \\
Substantivo & vaga & Externa & Verbo & estudar & Externa \\
Substantivo & gráfico & Externa & Verbo & fotografar & Externa \\
Substantivo & whatsapp & Externa & Verbo & recomendar & Externa \\
Substantivo & plano & Externa & Verbo & acompanhar & Externa \\
Substantivo & edital & Externa & Verbo & ajudar & Externa \\
Substantivo & tempo & Externa & Verbo & funcionar & Externa \\
Substantivo & estudo & Externa & Verbo & colocar & Externa \\
Substantivo & planejamento & Externa & Verbo & fraudar & Externa \\
Substantivo & data & Externa & Verbo & faltar & Externa \\
Substantivo & assunto & Interna & Verbo & visualizar & Interna \\
Substantivo & alerta & Interna & Verbo & completar & Interna \\
Substantivo & página & Interna & Verbo & delimitar & Interna \\
Substantivo & facebook & Interna & Verbo & orientar & Interna \\
Substantivo & pesquisa & Interna & Verbo & extrapolar & Interna \\
Substantivo & cidadão & Interna & Verbo & personalizar & Interna \\
Substantivo & grupo & Interna & Verbo & relacionar & Interna \\
Substantivo & requerimento & Interna & Verbo & simular & Interna \\
Substantivo & transporte & Interna & Verbo & avançar & Interna \\
Substantivo & identificação & Interna & Verbo & supervisionar & Interna
\end{tabular}

\footnotetext{
${ }^{2}<$ https://play.google.com/store/apps/category/EDUCATION $>$

${ }^{3}<$ https://play.google.com/store/apps/details?id=br.gov.mec.sisu $>$

${ }^{4}<$ https://play.google.com/store/apps/details?id=com.newsoftware.gabaritar $>$
} 
Além da definição das palavras a serem utilizadas durante a elicitação, preparamos 4 formulários, a saber: (i) formulário de identificação (FI) para que os participantes respondessem no início do estudo; (ii) formulários de avaliação da técnica usada (FA), para serem respondidos no final do estudo; (iii) formulários de elicitação (FE) no qual os participantes deviam escrever os requisitos criados; (iv) formulário de validação de requisitos (FV) no qual os participantes avaliaram os requisitos de acordo com os critérios de utilidade e originalidade. Estes formulários são ilustrados na Figura 3.

Figura 3: Formulários usados no estudo: (1) Formulário de identificação; (2) Formulário de elicitação com entrevista; (3) Formulário de elicitação com a técnica combinacional; (4) Formulário de avaliação dos requisitos;

(5) Formulário de avaliação da técnica usando entrevista; e (6) Formulário de avaliação da técnica usando criatividade combinacional

\section{1) Formulário de Identificação}

Este formulário visa a elaboração de requisitos para o sistema acadêmico Sigaa. Siga as instruções para levantar requisitos e depois avaliar a técnica usada.

1 - Qual o seu primeiro e último nome?

2 - Ano de nascimento

3 - Considerando o Sistema Sigaa, como você avalia a dificuldade de se criar funcionalidades (ou características de qualidade) inovadoras? Aqui, o conceito de "inovador" significa útil e inesperado.

É fácil criar funcionalidades inovadoras para o Sigaa.

É difícil criar funcionalidades inovadoras para o Sigaa. Outro

4 - Justifique sua resposta:

\section{2) Formulário de Elicitação usando Entrevista}

Escreva até 3 requisitos inovadores (útil e inesperado) para o sistema Sigaa. Utilize a seguinte estrutura textual: "O sistema deve..." Requisito 1

\section{Requisito 2}

$\longrightarrow$

\section{Requisito 3}

\section{3) Formulário de Elicitação usando Criatividade Combinacional}

Escreva até 3 requisitos inovadores (útil e inesperado) para o sistema Sigaa. Utilize a seguinte estrutura textual: "O sistema deve..."

Cada requisito deve obrigatoriamente conter pelo menos um VERBO da lista de verbos e pelo menos um SUBSTANTIVO da lista de substantivos abaixo.

Você pode flexionar os verbos e substantivos da maneira apropriada para concordar com o sujeito e objeto da frase, por exemplo, se o verbo é EDITAR e o substantivo é ALUNO, você pode criar o seguinte requisito: $\mathrm{O}$ sistema deve possibilitar que o aluno edite os horários no qual ele está disponível para participar de atividades extra curriculares. Lista de substantivos: disciplina, vaga, gráfico, whatsapp, plano, edital, tempo, estudo, planejamento, data, assunto, alerta, página, facebook, pesquisa, cidadão, grupo, requerimento, transporte, identificação

Lista de verbos: controlar, estudar, fotografar, recomendar, acompanhar, ajudar, funcionar, colocar, fraudar, faltar, visualizar, completar, delimitar, orientar, extrapolar, personalizar, relacionar, simular, avançar, supervisionar

Requisito 1

\section{Requisito 2}

\section{Requisito 3}

4) Formulário de Avaliação de Requisitos para o Sigaa

Avalie cada sentença de requisito abaixo de acordo com os critérios de Utilidade e Originalidade (inesperado). Pontue estes critérios usando a seguinte escala: 1- Absolutamente não concordo; 2- Não concordo; 3Neutro ou indiferente; 4- Concordo; 5- Concordo totalmente

\begin{tabular}{|l|l|l|}
\hline Requisito & O requisito proposto é útil. & O requisito proposto é original. \\
\hline Requisito 1 & & \\
\hline Requisito 2 & & \\
\hline Requisito 3 & & \\
\hline
\end{tabular}

5) Formulário de Avaliação da Técnica de Elicitação usando Entrevista

1 - Qual o seu primeiro e último nome?

2 - Como você avalia a dificuldade/facilidade em criar requisitos livremente, sem ter qualquer critério limitante ou orientador?

$\square$ Não ter critérios orientadores/limitantes dificultou o meu processo criativo Não ter critérios orientadores/limitantes facilitou o meu processo criativo Outro

3 - Justifique sua resposta

4 - Críticas e sugestões quanto a criar requisitos livremente

5 - Quanto a avaliação da utilidade e originalidade dos requisitos, é verdade afirmar:

$\square$ Foi difícil analisar o critério de utilidade

Foi fácil analisar o critério de utilidade

Foi difícil analisar o critério de originalidade

Foi fácil analisar o critério de originalidade

Se fossem menos requisitos eu teria analisado cada um deles mais apropriadamente

Eu teria facilmente analisado uma quantidade maior de requisitos

Outro

6 - Críticas e sugestões quanto a avaliação dos critérios de utilidade e originalidade

\section{6) Formulário de Avaliação da Técnica de Elicitação usando} Criatividade Combinacional

1 - Qual o seu primeiro e último nome?

2 - Como você avalia a dificuldade/facilidade em ter de usar um substantivo e verbo das listas oferecidas para criar requisitos?

$\square$ Estas listas dificultaram o meu processo criativo

Estas listas facilitaram o meu processo criativo

$\square$ Outro

3 - Justifique sua resposta

4 - Críticas e sugestões quanto a criar requisitos usando as listas

5 - Quanto a avaliação da utilidade e originalidade dos requisitos, verdade afirmar:

Foi difícil analisar o critério de utilidade

Foi fácil analisar o critério de utilidade

Foi dificil analisar o critério de originalidade

Foi fácil analisar o critério de originalidade

$\checkmark$ Se fossem menos requisitos eu teria analisado cada um deles mais apropriadamente

Eu teria facilmente analisado uma quantidade maior de requisitos Outro

6 - Críticas e sugestões quanto a avaliação dos critérios de utilidade e originalidade 
Há duas versões dos formulários FA e FE, pois os respondentes foram agrupados em dois conjuntos, um realizou a elicitação com base na técnica de criatividade combinacional enquanto o outro respondeu a solicitação para escrever requisitos úteis e originais, visto que são usuários assíduos do sistema, e assim possuem algumas demandas intrínsecas as suas necessidades diárias. Chamamos essa segunda técnica de entrevista, uma vez que o formulário não foi elaborado com o intuito de ter um significado estatístico, e possui apenas uma questão aberta. Após todos os recursos estarem preparados, o engenheiro de requisitos convidou 21 usuários para uma reunião de elicitação, dos quais 20 confirmaram a presença.

\subsection{Execução da elicitação e avaliação dos novos requisitos}

Finalizadas as tarefas associadas a preparação da elicitação, o engenheiro de requisitos disponibilizou o formulário para criação de novos requisitos. A elicitação ocorreu em uma reunião presencial com 20 usuários do Sigaa. Estes usuários são alunos do curso de Tecnologia da Informação da UFRN. Cada um deles usou um computador com acesso aos formulários.

O engenheiro de requisitos conduziu toda a reunião. Primeiramente, ele contextualizou os participantes, informando do que consistiam as duas técnicas de elicitação, sem mencionar qualquer preferência por nenhuma delas, e que o papel que eles iriam desempenhar era o de usuários do Sigaa que possuem várias demandas para gerenciar suas vidas acadêmicas. Foi explicado também que os participantes presentes iriam ser divididos em dois conjuntos, mas que cada um (individualmente) iria realizar todas as atividades referente a somente uma das técnicas. O engenheiro de requisitos enfatizou que eles não poderiam conversar entre si sobre as funcionalidades atuais do sistema, as ideias que estavam tendo, nem sobre quais palavras iriam usar.

Os participantes dos conjuntos foram escolhidos de acordo com a ordem alfabética de seus nomes, de A a J ficou no grupo 1 e de $\mathrm{L}$ a $\mathrm{Z}$ ficou no grupo 2, esta divisão resultou em dois grupos com quantidades iguais (10 e 10). Entretanto, três pessoas se atrasaram, e não participaram da etapa inicial que foi de elicitação. Porém, participaram da etapa de validar os requisitos criados. A consequência disto é que menos requisitos foram criados, mas mantivemos a quantidade de 5 avaliações por requisito.

Nos formulários de elicitação e validação (como visto na Figura 3), há as explicações sobre como preenchêlos. No formulário referente a técnica de elicitação baseada na criatividade combinacional, as regras para a criação dos requisitos foram: (i) Cada participante pode sugerir até 3 (três) frases curtas que representem uma nova funcionalidade para o sistema em questão; (ii) Cada frase deve conter pelo menos um substantivo e um verbo retirado de cada lista apresentada; (iii) Os verbos retirados da lista podem ser flexionados em outra forma ou tempo verbal. Os substantivos também podem ser flexionados segundo grau, gênero ou número; (iv) A frase pode incluir também outros verbos e substantivos.

Após as explicações e sanadas as dúvidas, o engenheiro de requisitos autorizou os participantes a responderem o formulário de identificação (FI). Quando todos sinalizaram o término, eles acessaram o formulário de elicitação (FE), neste momento realizamos a contagem do tempo de resposta. Os participantes finalizaram a criação decorridos apenas 23 minutos, e a maioria deles criou o número máximo de requisitos solicitados.

Finalizada esta etapa, o engenheiro de requisitos coletou os requisitos formulados e criou 4 listas de requisitos para serem validados segundo os critérios de utilidade e originalidade. Cada uma das listas possui em torno de 14 requisitos. Esta divisão foi realizada para que cada participante não tivesse que avaliar um número muito grande de requisitos e assim tornar o processo enfadonho e cansativo. Com a divisão, as duas primeiras listas contém os requisitos dos participantes que não usaram a técnica e as duas últimas listas contém os requisitos dos participantes que utilizaram a técnica de criatividade. As primeiras duas listas foram entregues para os participantes que utilizaram a técnica de criatividade enquanto as duas últimas foram entregues aos participantes que não usaram a técnica. Dado que 3 participantes chegaram no final da elicitação, eles foram incluídos na validação e com isto, cada requisito foi validado por 5 participantes.

Neste momento o engenheiro de requisitos instruiu os participantes sobre como pontuar os requisitos e que não deveria haver comunicação entre eles durante esta etapa. Cada participante avaliou os requisitos escritos por outros participantes, atribuindo uma pontuação de 1 a 5 para cada um deles. A Tabela 3, apresenta os requisitos criados e sua pontuação média, detalhados na próxima seção.

Após esta etapa, foi solicitado que cada participante respondesse o formulário final de avaliação da técnica

Revista Brasileira de Computação Aplicada (ISSN 2176-6649), Passo Fundo, v. 9, n. 4, p. 105-119, dez. 2017113 
usada (FA). A execução do experimento, incluindo os tempos de divisão dos grupos, instrução, preenchimento de formulário inicial, elicitação, validação e preenchimento de avaliação final teve duração de 1 hora e 6 minutos.

\subsection{Resultados e discussão}

A tabela 3 resume os dados obtidos com a elicitação e validação, ou seja, os requisitos elaborados e a média das 5 pontuações que cada requisito obteve para os critérios de utilidade e originalidade. A coluna Técnica indica se o requisito foi criado pela técnica baseada em criatividade (TC) ou pela técnica baseada em entrevista (TE). Assim, 21 requisitos foram elaborados por 8 participantes usando TE enquanto 24 requisitos criados por 9 participantes usando TC. Desta forma, na média, a mesma quantidade de requisitos foi criada pelos participantes que usaram TC e TE. Em relação ao tempo gasto, os que usaram TC demoraram mais, cerca de 23 minutos, enquanto os que usaram TE demoraram 14 minutos.

Para indicar se um requisito é considerado original ou útil, nós assumimos que a média obtida pela avaliação dos 5 avaliadores deveria ser maior ou igual a 3,6. Esta média leva em conta que teríamos, assim, uma concordância (notas 4 ou 5) da maioria dos avaliadores que o dado requisito é original ou útil e nenhuma avaliação discordando (notas 1 e 2) disto. Em relação aos requisitos elaborados com TC e TE, temos que:

i) 3 sentenças foram descartadas dentre os requisitos elaborados com TC, porque não continham pelo menos uma palavra das listas de verbos e uma da lista de substantivos, desta forma, foram considerados um total de 21 requisitos para ambas as técnicas;

ii) Quanto a originalidade, TE produziu 6 (28,5\%) requisitos avaliados como originais enquanto TC produziu 8 $(38 \%)$;

iii) O índice de originalidade dos requisitos (i.e. a média das médias para a originalidade) ficou em 3,22 usando TE enquanto em TC este índice foi de 3,23;

iv) Considerando apenas os requisitos tidos como originais, este índice de originalidade foi de 4,1 usando TE e 3,9 usando TC;

v) Quanto a utilidade, TE produziu 16 (76\%) requisitos avaliados como úteis enquanto TC produziu $10(47,6 \%)$;

vi) O índice de utilidade dos requisitos ficou em 4,01 usando TE enquanto em TC este índice foi de 3,42;

vii) Considerando apenas os requisitos tidos como úteis, este índice de utilidade foi de 4,3 usando TE e 4,0 usando $\mathrm{TC}$;

viii) Considerando ambos os critérios (originalidade e utilidade), em TE, 23\% (5 de 21) dos requisitos obtiveram uma pontuação maior que 3,6, enquanto em TC, 19\% (4 de 21) dos requisitos obtiveram esta pontuação.

Podemos perceber então que a técnica de TC gerou uma quantidade bem menor de requisitos considerados úteis do que a TE. Em relação a originalidade e a atender a ambos os critérios não houve diferença significativa, e embora TC tenha produzido mais requisitos avaliados como originais, TE produziu mais requisitos que atende aos dois critérios. Os índices de originalidade e utilidade nos indicam que na média, os requisitos produzidos por TE foram melhor avaliados tanto em relação a originalidade quanto a utilidade.

Se por um lado estes números indicam que a técnica baseada em criatividade produz requisitos úteis e originais, por outro lado mostra que ela não é melhor do que solicitar diretamente aos stakeholders tais requisitos. Além disso, comparando este resultado com os resultados dos trabalhos relacionados na Tabela 1 podemos observar que este estudo e o trabalho relatado em [12] são capazes de criar requisitos em pouco tempo, enquanto as demais técnicas, embora tenham gerado mais requisitos, gastaram mais tempo na elaboração dos mesmos, o que pode deixar a abordagem mais difícil e custosa de ser aplicada.

Os substantivos e verbos destacados na Tabela 3 indicam sua presença nas lista de substantivos e verbos usadas na TC. A Tabela 4 indica a quantidade de vezes que cada palavra foi usada. Podemos perceber uma preferência pelas palavras disciplina (20), facebook (7), visualizar (5), sendo elas respectivamente um substantivo externo, um substantivo incluído manualmente, e um verbo interno. É interessante perceber que algumas das 
Tabela 3: Resultados da elicitação para o Sigaa

\begin{tabular}{|c|c|c|c|c|}
\hline Item & Técnica & Requisito & $\begin{array}{c}\text { Média } \\
\text { Utilidade }\end{array}$ & $\begin{array}{l}\text { Média } \\
\text { Originali- } \\
\text { dade }\end{array}$ \\
\hline 1 & TE & $\begin{array}{l}\text { O sistema deve oferecer uma integração com APIs de redes sociais (Facebook, Google+, Twitter...) para notificar os alunos } \\
\text { e professores através das redes, as notificações preferenciais são notícias e avisos de mudança de nota ou de frequência. }\end{array}$ & 4.6 & 3 \\
\hline 2 & TE & O sistema deve calcular uma expectativa de notas para que o aluno passe por média. & 4.6 & 3 \\
\hline 3 & TE & $\begin{array}{l}\text { O sistema deve possuir integração com o Google Calendar para permitir o registro de datas importantes, como provas e } \\
\text { trabalhos. }\end{array}$ & 4 & 3.2 \\
\hline 4 & TE & $\begin{array}{l}\text { O sistema deve mandar um e-mail para um aluno quando sua frequência estiver perto de ficar menor que } 75 \% \text {. Mostrando, } \\
\text { assim, para o aluno que ele tem que ir para as aulas, ou ele vai reprovar por faltar. }\end{array}$ & 4.6 & 3.8 \\
\hline 5 & TE & O sistema deve fornecer um módulo para administração mais direta de centros, departamentos, institutos e afins. & 3.6 & 2.8 \\
\hline 6 & $\mathrm{TE}$ & $\begin{array}{l}\text { O sistema deve fornecer informações referentes ao ambiente físico da universidade, utilizando mapas para mostrar nome de } \\
\text { estruturas, eventos que ocorram no campus e áreas de convívio comum }\end{array}$ & 4.6 & 3.6 \\
\hline 7 & $\mathrm{TE}$ & $\begin{array}{l}\text { Permitir a requisição e reserva de salas por alunos e manter um controle sobre o sistema de entrega e devolução de chaves } \\
\text { para salas. Deve existir uma lista de salas disponíveis a reservas por alunos. }\end{array}$ & 4 & 2.8 \\
\hline 8 & TE & $\begin{array}{l}\text { O sistema deve notificar uma vez o aluno vinculado a uma turma do semestre atual (quando esse aluno for reprovar por faltar } \\
\text { na turma caso ele falte mais } 4 \text { aulas) enviando um e-mail ao endereço de e-mail do cadastro desse aluno, informando-o que } \\
\text { se ele faltar mais } 4 \text { aulas dessa turma, ele estará reprovado nessa turma por falta. }\end{array}$ & 4.2 & 3.2 \\
\hline 9 & $\mathrm{TE}$ & $\begin{array}{l}\text { O sistema deve oferecer um aplicativo mobile que somente é utilizado para organizar as tarefas e provas do aluno, notificando } \\
\text { ele sempre que uma tarefa ou prova está perto de ter seu prazo concluído, as tarefas já enviadas não devem mais notificar os } \\
\text { alunos. }\end{array}$ & 4 & 2.6 \\
\hline 10 & $\mathrm{TE}$ & $\begin{array}{l}\text { O sistema deve ter uma opção de ver a prova corrigida com comentários do professor, respostas corretas e explicação da } \\
\text { resposta que o aluno deu caso ele queira (vista de prova online). }\end{array}$ & 4.8 & 4.2 \\
\hline 11 & $\mathrm{TE}$ & $\begin{array}{l}\text { O sistema deve deixar baixar os arquivos inseridos nas aulas pelo e-mail, quando mandar uma mensagem pelo e-mail que } \\
\text { novos arquivos foram inseridos na disciplina. }\end{array}$ & 4.4 & 2.8 \\
\hline 12 & TE & O sistema deve permitir a solução de mais demandas através do portal. & 3.2 & 2.8 \\
\hline 13 & TE & $\begin{array}{l}\text { O sistema deve monitorar o rendimento acadêmico dos usuários e, em caso de notas abaixo da média ou aspectos nega- } \\
\text { tivos no histórico, pedir uma justificativa opcional por parte do aluno. Professores e demais interessados podem avaliar a } \\
\text { justificativa e contactar o aluno para a resolução dos problemas. }\end{array}$ & 4.4 & 4.2 \\
\hline 14 & TE & $\begin{array}{l}\text { O sistema deve, basendo-se nos hábitos alimentares dos servidores, calcular a esperança deste utilizar o serviço de refeições } \\
\text { do Restaurante Universitário (RU) de modo a manter um valor minimo de desperdício. }\end{array}$ & 3.4 & 4.4 \\
\hline 15 & TE & $\begin{array}{l}\text { O sistema deve permitir que um aluno vinculado a uma turma do semestre atual possa avaliar cada tópico de aula dessa } \\
\text { turma. Informando uma nota entre } 1 \text { a } 5 \text { estrelas (valor inteiro apenas) e adicionar comentários relacionados ao tópico. }\end{array}$ & 3 & 2.8 \\
\hline 16 & TE & $\begin{array}{l}\text { O sistema deve oferecer um sistema de ranqueamento para o aluno, mostrando a ele qual a posição que ele se encontra } \\
\text { comparado com todos os alunos e ex-alunos do curso. Não deve-se mostrar o nome dos outros alunos, somente suas } \\
\text { pontuações e posições. }\end{array}$ & 2.2 & 2.4 \\
\hline 17 & TE & $\begin{array}{l}\text { O sistema deve possuir uma agenda de estudos personalizada que possua os tópicos de aula e assuntos de todas as matérias } \\
\text { do aluno e que o mesmo possa indicar quais tópicos estudou e quais ainda vai estudar. }\end{array}$ & 4.4 & 3.4 \\
\hline 18 & TE & O sistema deve mandar um aviso por e-mail quando tiver faltando um dia para alguma tarefa/prova/trabalho. & 4.8 & 3.4 \\
\hline 19 & TE & O sistema deve fornecer uma maior integração entre os módulos existentes. & 3 & 1.4 \\
\hline 20 & TE & $\begin{array}{l}\text { O sistema deve permitir a criação e divulgação de grupos de estudo coletivos criados pelos alunos, disponibilizando local, } \\
\text { data e hora além do tema do grupo de estudo. Participantes não precisam ser, necessariamente, do mesmo curso. }\end{array}$ & 4.4 & 3.4 \\
\hline 21 & TE & $\begin{array}{l}\text { O sistema deve, baseando-se nas matrículas em disciplinas e atividades de alunos (como bolsas de monitoria, apoio técnico, } \\
\text { ou outros) e associado a hábitos de alimentação previamente registrados, calcular a esperança de um aluno utilizar o serviço } \\
\text { de refeições do Restaurante Universitário (RU) de modo a manter um valor mínimo de desperdício. }\end{array}$ & 4 & 4.4 \\
\hline 22 & TC & O sistema deve permitir que o aluno acompanhe as notícias geradas pelo sigaa pelo facebook. & 2.6 & 3.8 \\
\hline 23 & TC & O sistema deve permitir o controle do planejamento de uma disciplina. & 3.4 & 3 \\
\hline 24 & TC & $\begin{array}{l}\text { O sistema deve permitir que acompanhe os alertas sobre notícias cadastradas na disciplina, através das notificações do } \\
\text { Facebook. }\end{array}$ & 3.2 & 3.6 \\
\hline 25 & TC & $\begin{array}{l}\text { O sistema deve possuir um meio de criação de grupos de chats multidisciplinares mas com conteúdo parecido, supervisi- } \\
\text { onados pelos professores responsáveis pelas disciplinas, monitores e/ou moderadores do chat, funcionando semelhante ao } \\
\text { que o whatsapp faz, tanto em usabilidade quanto em visual, de forma a deixar os alunos mais familiarizados com o chat. }\end{array}$ & 3.8 & 3.8 \\
\hline 26 & TC & O sistema deve controlar o tempo que o aluno gasta estudando uma determinada disciplina. & 3 & 3.6 \\
\hline 27 & TC & $\begin{array}{l}\text { O sistema deve permitir que o aluno controle o seu plano de estudo semanal, associando tópicos dados em aula a horários } \\
\text { de estudo definidos. }\end{array}$ & 4.2 & 4.2 \\
\hline 28 & TC & $\begin{array}{l}\text { O sistema deve possibilitar o aluno visualizar planos de matrículas possíveis de acordo com as disciplinas ofertadas no } \\
\text { semestre posterior e que são obrigatórias na grade curricular do aluno. }\end{array}$ & 3.8 & 3.4 \\
\hline 29 & TC & O sistema deve permitir que aluno controle chats das disciplinas. & 2.2 & 2 \\
\hline 30 & TC & O sistema deve permitir que o aluno possa visualizar alertas de provas e atividades em forma de pop up. & 4.2 & 3 \\
\hline 31 & TC & O sistema deve permitir o aluno visualizar um assunto de uma disciplina. & 3.2 & 2.6 \\
\hline 32 & $\mathrm{TC}$ & O sistema deve relacionar um grupo do Whatsapp ao fórum da disciplina. & 3.2 & 3.2 \\
\hline 33 & TC & $\begin{array}{l}\text { O sistema deve possuir meios gráficos de dar feedback ao aluno no momento da matrícula nas disciplinas de forma a ajudá- } \\
\text { lo e orientá-lo de quais disciplinas devem ser pagas juntas, não só pelo peso da carga horária, mas pelo índice de reprovações } \\
\text { e trancamentos anteriores. }\end{array}$ & 4.4 & 4.4 \\
\hline 34 & TC & O sistema deve recomendar disciplinas optativas de acordo com a página do facebook do aluno. & 1.8 & 4 \\
\hline 35 & TC & $\begin{array}{l}\text { O sistema deve permitir a criação automática de um grupo no Facebook relacionado a um trabalho/atividade proposta pelo } \\
\text { professor com os componentes definidos para melhor comunicação. }\end{array}$ & 2.2 & 3 \\
\hline 36 & TC & O Sistema deve simular um gráfico com a evolução das notas do aluno para as disciplinas. & 3.8 & 2 \\
\hline 37 & TC & O sistema deve permitir que o aluno recomende uma disciplina para outro usuário do sigaa através do sistema. & 3.8 & 2.8 \\
\hline 38 & TC & O sistema deve recomendar um plano de estudos para o aluno com base nas disciplinas que ele está pagando. & 4.2 & 4 \\
\hline 39 & $\mathrm{TC}$ & O sistema deve permitir que os usuários acompanhem os horários dos transportes públicos do campus. & 4 & 2.4 \\
\hline 40 & TC & $\begin{array}{l}\text { O sistema deve possuir no seu aplicativo mobile, um modo de planejamento interno do aluno, dando "to do lists", e até } \\
\text { algo próximo ao que o trello faz, mas unindo as disciplinas automaticamente, de forma a todo nova prova ou atividade, ser } \\
\text { colocada no "to do", e o aluno ficará responsável de colocar no "doing"e no "done"de forma a ser alertado caso demore } \\
\text { demais para começar o acompanhamento da atividade, ou se não chegar a visualizá-lo por um tempo predefinido. }\end{array}$ & 4.4 & 3.2 \\
\hline 41 & TC & O sistema deve ajudar no planejamento e no cumprimento das datas dos trabalho das disciplinas. & 3.2 & 2.8 \\
\hline 42 & $\mathrm{TC}$ & O sistema deve permitir a personalização da visualização de uma disciplina. & 3.2 & 3 \\
\hline
\end{tabular}

Revista Brasileira de Computação Aplicada (ISSN 2176-6649), Passo Fundo, v. 9, n. 4, p. 105-119, dez. 2017115 
palavras (6 substantivos e 4 verbos) também aparecem nos requisitos elaborados com TE (em 14 ocorrências), embora o engenheiro de requisitos não tenha induzido-os a pensar em funcionalidades associadas a elas. Um fato curioso é que mais palavras (9) das fontes internas não foram usadas nenhuma vez enquanto que apenas 6 da fonte externa não foram usadas. Dentre as palavras que foram excluídas pelo engenheiro de requisitos, apenas o verbo ficar foi usado, mesmo assim uma única vez.

Tabela 4: Distribuição do uso das palavras nos requisitos

\begin{tabular}{l|l|l|l|ll|l|l|l|l} 
Classificação & Palavra & Origem & TC & TE & Classificação & Palavra & Origem & TC & TE \\
\hline Substantivo & disciplina & Externa & 18 & 2 & & Verbo & controlar & Externa & 4 \\
Substantivo & vaga & Externa & 0 & 0 & Verbo & estudar & Externa & 0 & 1 \\
Substantivo & gráfico & Externa & 3 & 0 & Verbo & fotografar & Externa & 0 & 0 \\
Substantivo & whatsapp & Externa & 2 & 0 & Verbo & recomendar & Externa & 3 & 0 \\
Substantivo & plano & Externa & 3 & 0 & Verbo & acompanhar & Externa & 5 & 0 \\
Substantivo & edital & Externa & 0 & 0 & Verbo & ajudar & Externa & 2 & 0 \\
Substantivo & tempo & Externa & 2 & 0 & Verbo & funcionar & Externa & 1 & 0 \\
Substantivo & estudo & Externa & 3 & 2 & Verbo & colocar & Externa & 1 & 0 \\
Substantivo & planejamento & Externa & 3 & 0 & Verbo & fraudar & Externa & 0 & 0 \\
Substantivo & data & Externa & 2 & 2 & Verbo & faltar & Externa & 0 & 2 \\
Substantivo & assunto & Interna & 2 & 1 & Verbo & visualizar & Interna & 5 & 0 \\
Substantivo & alerta & Interna & 4 & 0 & Verbo & completar & Interna & 0 & 0 \\
Substantivo & página & Interna & 1 & 0 & Verbo & delimitar & Interna & 0 & 0 \\
Substantivo & facebook & Interna & 6 & 1 & Verbo & orientar & Interna & 1 & 0 \\
Substantivo & pesquisa & Interna & 0 & 0 & Verbo & extrapolar & Interna & 0 & 0 \\
Substantivo & cidadão & Interna & 0 & 0 & Verbo & personalizar & Interna & 1 & 1 \\
Substantivo & grupo & Interna & 3 & 1 & Verbo & relacionar & Interna & 0 & 0 \\
Substantivo & requerimento & Interna & 0 & 0 & Verbo & simular & Interna & 2 & 0 \\
Substantivo & transporte & Interna & 1 & 0 & Verbo & avançar & Interna & 0 & 0 \\
Substantivo & identificação & Interna & 1 & 0 & Verbo & supervisionar & Interna & 0 & 0
\end{tabular}

Antes da elaboração dos requisitos (e dos participantes saberem qual técnica iriam usar), no formulário de identificação (FI), foi perguntado aos participantes como eles avaliavam a dificuldade de se criar requisitos inovadores para o Sigaa: 55,6\% dos participantes que usaram TC responderam ser fácil criar funcionalidades inovadoras enquanto que a maioria dos que usaram TE $(75 \%)$ responderam ser difícil. Mesmo considerando difícil, este segundo grupo conseguiu atingir resultados melhores do que o grupo que considerava ser uma tarefa fácil. Isso nos faz levantar algumas questões: a TC dificultou a criação por aqueles que achavam fácil? ou por achar fácil, tais participantes não se esforçaram tanto quanto o outro grupo que considerava a tarefa difícil?

Depois da elaboração e validação dos requisitos, no formulário de avaliação da técnica (FA) foi perguntado aos participantes como eles avaliaram a dificuldade em criar requisitos a partir das listas de palavras (no caso de TC) e livremente, sem critérios limitantes ou orientadores (no caso de TE). Em ambos os grupos 50\% dos participantes disseram facilitar e $50 \%$ disseram dificultar. As justificativas do grupo que usou TC giraram em torno das seguintes: "Facilitam como um guia, mas limitam ideias independentes" e "Uma vez que tenho dificuldades de criar ideias inovadoras, a utilização de substantivos e verbos ajudou a ativar conhecimentos anteriores $e$ consequentemente ter ideias mais criativas e úteis". Enquanto que os participantes que usaram TE justificaram com respostas tais como: "Sem qualquer fator limitante, ideias bastante ousadas podem ser ouvidas e refinadas" e "Permite uma maior liberdade na escrita dos requisitos, desde que o usuário tenha experiência com o sistema e tenha conhecimento de outras tecnologias e sistemas de domínios semelhantes".

Ao perguntar por sugestões, eles disseram que o processo deveria ser misto: "Acredito que o ideal é criar requisitos com e sem critérios orientadores/limitantes. Pois de certa forma os critérios orientam, mas limitam. Sem eles talvez fique-se sem rumo na criação. Então, os dois, se complementam" e "Criar requisitos livremente dá muita liberdade e pode acabar misturando um requisito com outro e a pessoa se perder nas ideias. Poderia ser criado um limite ou área de abrangência para a criação de requisitos: limitar a área, mas não necessariamente as ideias".

Em relação a validação, a maioria dos participantes julgou ser fácil avaliar o critério de utilidade (16 de 20), e difícil avaliar o critério de originalidade (12 de 20). Dentre estes últimos, 8 foram participantes que avaliaram 
os requisitos criados usando TC, i.e. talvez aqueles que também consideraram difícil a tarefa de criar requisitos inovadores. As sugestões e críticas dadas quanto a validação usando os critérios de utilidade e originalidade foram principalmente (10 de 17) para esclarecer o critério de originalidade, tal como: "A originalidade seria mais facilmente avaliada se fosse definido um critério do que significa ser original, assim teria algo para se basear sobre a nota" e a segunda preocupação é que alguns requisitos foram julgados como vagos e mal escritos, tal como: "Algumas descrições ficaram bem vagas".

\subsection{Ameaças à validade do estudo}

Consideramos as seguintes ameaças ao nosso estudo: (i) os participantes têm um perfil muito similar, são usuários do sistema, há mais ou menos o mesmo tempo, porém eles divergem em experiência tanto de uso quanto de desenvolvimento de sistemas similares. Esta ameaça foi mitigada pela escolha aleatória de quais participantes estariam em cada grupo. Entretanto, ter uma maior variedade de perfis pode fazer o processo de criação mais efetivo. (ii) Nem todos os participantes têm a habilidade de escrever requisitos de forma clara e objetiva, o que pode ter levado alguns dos requisitos a não serem bem entendidos. Esta ameaça foi mitigada por deixar que todas as sentenças levantadas por ambas as técnicas fossem avaliadas e por orientar os participantes a classificálas negativamente. Dessa forma, as duas técnicas correram o mesmo risco de ter seus requisitos mal avaliados. Lembrando que três requisitos foram excluídos da lista obtida com TC porque eles não atendiam o critério mínimo de ter palavras das listas de verbos e substantivos. (iii) Os participantes tiveram muitas dúvidas para avaliar o critério de originalidade. Esta ameaça foi mitigada, por oferecer uma pequena explicação do significado deste critério, porém ainda assim, os participantes consideraram que a escala de pontuação poderia ser mais direcionada para indicar quais os parâmetros a serem avaliados neste critério.

\subsection{Lições aprendidas}

A partir das experiências relatadas neste artigo, podemos citar as principais lições aprendidas: i) Utilizar a escala Likert pode não ser a melhor opção para avaliar os requisitos gerados. É importante analisar outras formas de escalas de medição tais como VAS (Visual Analogue Scales), escala numérica e escala Guttman [23] ou mesmo alguma personalizada para que deixe mais claro o significado de cada valor do critério, tal como em [24]. ii) Apesar de haver um número considerável de stakeholders participantes, o fato deles estarem propondo novos requisitos de forma individual pode limitar a capacidade de pensar de forma criativa. É natural que discussões entre os participantes, a fim de entender melhor as ideias e requisitos, façam um filtro inicial ou mesmo aperfeiçoem as propostas. Em trabalhos futuros iremos buscar alternativas para incluir discussões em grupos de usuários para que os mesmos possam explicar suas ideias com mais detalhes. Além disso, o fato de ter solicitado para que eles incluíssem diretamente no máximo 3 requisitos no formulário fez com que eles submetessem os três primeiros requisitos pensados, não refletindo por mais tempo sobre outros requisitos e quais os melhores dentre eles.

\section{Conclusão}

Neste trabalho experimentamos uma estratégia para elicitação de requisitos baseada na perspectiva da criatividade combinacional. Esta estratégia sugere extrair palavras relevantes de duas fontes de dados textuais utilizando Processamento de Linguagem Natural. A primeira fonte de dados está diretamente relacionada ao domínio da aplicação (a documentação do sistema, por exemplo) enquanto a segunda fonte está associada a dados gerais sobre o domínio ou correlato (obtidos livremente da internet, por exemplo). Ambas as fontes são escolhas do engenheiro de requisitos, responsável por conduzir as tarefas propostas pela abordagem. De posse das palavras mais relevantes dessas fontes de dados, é selecionado um conjunto de substantivos e outro de verbos e disponibilizados aos stakeholders, especialistas no sistema dos quais se deseja elicitar os novos requisitos. Esses stakeholders devem combinar as palavras das listas e gerar frases/sentenças que expressem novos requisitos para o sistema. Após isso os participantes avaliam os requisitos sugeridos, atribuindo uma pontuação aos quesitos utilidade e originalidade.

A experimentação foi realizada no contexto de um Sistema Acadêmico, chamado Sigaa. O objetivo era comparar os resultados alcançados usando e não usando a abordagem baseada em criatividade combinacional. Ao final do experimento, constatamos que não houve diferença significativa na quantidade de requisitos obtidos nas duas técnicas e considerados ao mesmo tempo úteis e criativos. Entretanto, a técnica não-combinacional gerou uma

Revista Brasileira de Computação Aplicada (ISSN 2176-6649), Passo Fundo, v. 9, n. 4, p. 105-119, dez. 2017117 
quantidade maior de requisitos considerados úteis, ao mesmo tempo que tais requisitos apresentaram um índice de utilidade maior do que aqueles propostos pela técnica combinacional. Assim, podemos concluir que embora seja possível estimular o pensamento criativo utilizando essa abordagem, não há diferença significativa para outras abordagens, provavelmente porque outros fatores se sobrepuseram a escolha da técnica, como por exemplo, a demanda por novas funcionalidade já retida dos participantes.

Com este estudo, levantamos a necessidade de investigar quais fatores interferem nos resultados alcançados pelas técnicas de elicitação, principalmente com respeito a produção de requisitos criativos. No metamodelo definido em [13], já esboçamos alguns destes fatores, mas ainda se faz necessário realizar estudos experimentais que avaliem como se dá esta interferência e como gerenciá-la. É também necessário considerar a realização de novos experimentos com sistemas ou produtos fora da área acadêmica, e cujos participantes tenham perfis diversos para elaborar requisitos e para validá-los.

\section{Referências}

[1] CHENG, B. H.; ATLEE, J. M. Research directions in requirements engineering. In: IEEE COMPUTER SOCIETY. 2007 Future of Software Engineering. [S.1.], 2007. p. 285-303.

[2] BURNAY, C.; HORKOFF, J.; MAIDEN, N. Stimulating stakeholders' imagination: New creativity triggers for eliciting novel requirements. In: IEEE. Requirements Engineering Conference (RE), 2016 IEEE 24th International. [S.1.], 2016. p. 36-45.

[3] SAHA, S. K. et al. A systematic review on creativity techniques for requirements engineering. In: IEEE. Informatics, Electronics \& Vision (ICIEV), 2012 International Conference on. [S.1.], 2012. p. 34-39.

[4] BHOWMIK, T. et al. Automated support for combinational creativity in requirements engineering. In: IEEE. Requirements Engineering Conference (RE), 2014 IEEE 22nd International. [S.1.], 2014. p. 243-252.

[5] STERNBERG, R. J. Handbook of creativity. [S.1.]: Cambridge University Press, 1999.

[6] MAIDEN, N. et al. Requirements engineering as creative problem solving: A research agenda for idea finding. In: IEEE. Requirements Engineering Conference (RE), 2010 18th IEEE International. [S.1.], 2010. p. 57-66.

[7] LEMOS, J. et al. A systematic mapping study on creativity in requirements engineering. In: ACM. Proceedings of the 27th Annual ACM Symposium on Applied Computing. [S.1.], 2012. p. 1083-1088.

[8] HORKOFF, J.; MAIDEN, N. A. Creativity and conceptual modeling for requirements engineering. In: REFSQ Workshops. [S.1.: s.n.], 2015. p. 62-68.

[9] SEYFF, N. et al. Exploring how to use scenarios to discover requirements. Requirements Engineering, Springer, v. 14, n. 2, p. 91-111, 2009.

[10] MAIDEN, N.; GIZIKIS, A.; ROBERTSON, S. Provoking creativity: Imagine what your requirements could be like. Software, IEEE, IEEE, v. 21, n. 5, p. 68-75, 2004.

[11] VETTERLI, C. et al. From palaces to yurts: Why requirements engineering needs design thinking. Internet Computing, IEEE, IEEE, v. 17, n. 2, p. 91-94, 2013.

[12] PINTO, R. et al. Criatividade combinacional para geração de requisitos inovadores: Um relato de experiência. 18th Workshop on Requirements Engineering (WER), p. 592-605, 2015.

[13] PINTO, R. et al. A software process line for combinational creativity-based requirements elicitation. 19th International Conference on Enterprise Information Systems (ICEIS), 2017.

[14] NGUYEN, L.; SHANKS, G. A framework for understanding creativity in requirements engineering. Information and software technology, Elsevier, v. 51, n. 3, p. 655-662, 2009.

[15] BODEN, M. A. The creative mind: Myths and mechanisms. [S.1.]: Psychology Press, 2004. 
[16] MAIDEN, N. Requirements engineering as information search and idea discovery (keynote). In: IEEE. 2013 21st IEEE International Requirements Engineering Conference (RE). [S.1.], 2013. p. 1-1.

[17] SAKHNINI, V.; MICH, L.; BERRY, D. M. Group versus individual use of power-only epmcreate as a creativity enhancement technique for requirements elicitation. Empirical Software Engineering, Springer, v. 22, n. 4, p. 2001-2049, 2017.

[18] MICH, L.; ANESI, C.; BERRY, D. M. Applying a pragmatics-based creativity-fostering technique to requirements elicitation. Requirements Engineering, Springer, v. 10, n. 4, p. 262-275, 2005.

[19] MAIDEN, N. Systematic scenario walkthroughs with art-scene. Alexander \& Maiden, John Wiley, p. 166178, 2004.

[20] JOHANN, T. et al. Safe: A simple approach for feature extraction from app descriptions and app reviews. In: IEEE. Requirements Engineering Conference (RE), 2017 IEEE 25th International. [S.1.], 2017. p. 21-30.

[21] PORTUGAL, R. L. Q.; ROQUE, H.; LEITE, J. C. S. do P. A corpus builder: Retrieving raw data from github for knowledge reuse in requirements elicitation. In: SIMBig. [S.1.: s.n.], 2016. p. 48-54.

[22] BLEI, D. M.; NG, A. Y.; JORDAN, M. I. Latent dirichlet allocation. Journal of machine Learning research, v. 3, n. Jan, p. 993-1022, 2003.

[23] MATELL, M. S.; JACOBY, J. Is there an optimal number of alternatives for likert scale items? study. Educational and psychological measurement, v. 31, p. 657-674, 1971.

[24] MAIDEN, N.; GIZIKIS, A. Where do requirements come from? Software, IEEE, IEEE, v. 18, n. 5, p. 10-12, 2001. 